\title{
The evolving landscape in the therapy of acute myeloid leukemia
}

\author{
Grace L. Peloquin, Yi-Bin Chen, Amir T. Fathi ${ }^{\varpi}$ \\ Massachusetts General Hospital Cancer Center, Harvard Medical School, Boston, MA 02114, USA \\ $\square$ Correspondence: afathi@partners.org \\ Received June 11, 2013 Accepted July 25, 2013
}

\begin{abstract}
Acute myeloid leukemia ( $A M L)$ is a heterogeneous clonal disorder of myeloid precursors arrested in their maturation, creating a diverse disease entity with a wide range of responses to historically standard treatment approaches. While significant progress has been made in characterizing and individualizing the disease at diagnosis to optimally inform those affected, progress in treatment to reduce relapse and induce remission has been limited thus far. In addition to a brief summary of the factors that shape prognostication at diagnosis, this review attempts to expand on the current therapies under investigation that have shown promise in treating AML, including hypomethylating agents, gemtuzumab ozogamicin, FLT3 tyrosine kinase inhibitors, antisense oligonucleotides, and other novel therapies, including aurora kinases, mTOR and PI3 kinase inhibitors, PIM kinase inhibitors, HDAC inhibitors, and IDH targeted therapies. With these, and undoubtedly many others in the future, it is the hope that by combining more accurate prognostication with more effective therapies, patients will begin to have a different, and more complete, outlook on their disease that allows for safer and more successful treatment strategies.
\end{abstract}

KEYWORDS acute myeloid leukemia, hypomethylating, FLT3, gemtuzumab ozogamicin

\section{INTRODUCTION}

Acute myeloid leukemia (AML) consists of a group of diverse hematopoietic neoplasms characterized by clonal proliferation of myeloid precursors with a reduced capacity to differentiate into more mature cellular elements. Beyond the heterogeneity of the biology of AML, the response to treatment and overall survival of patients with AML ranges widely but remains poor overall. Certain factors can help shape prognostic risk at diagnosis, including age, performance status, as well as chromosomal and molecular alterations, but the success of conventional chemotherapy has been limited. Although induction chemotherapy leads to a complete remission in the majority of patients, relapse rates are high, with only $40 \%$ of patients younger than 60 years, and $10 \%-20 \%$ of older patients, remaining in remission at 5 years after diagnosis (Lowenberg et al., 1996, 1998, 1999). Given the current state of therapeutic options, novel therapeutic approaches are urgently needed and are being actively investigated. Many new treatments in development are targeted at genetic and molecular alterations that are thought to mediate leukemogenesis and/or affect patient prognosis. This review, while aware of the effectiveness of conventional chemotherapy, understands its limitations and seeks to both lay the current state of therapeutic approaches for AML and highlight innovative treatments that will hopefully improve upon current outcomes.

\section{CURRENT APPROACHES AT TREATMENT AND PROGNOSTICATION}

During the past few decades, remission induction chemotherapy combining infusional cytarabine and an anthracycline, typically idarubicin or daunorubicin, has become the standard of care for most patients in the US who are not participating in a clinical trial (Yates et al., 1982; Dillman et al., 1991; Rowe and Tallman, 1997). In an attempt to improve the rate of complete remission and decrease relapse, studies have tested alternative and higher doses of agents, as well as novel combinations of conventional chemotherapies (Arlin et al., 1990; Bishop et al., 1990; Berman et al., 1991; Vogler et al., 1992; Wiernik et al., 1992; Bishop et al., 1996; Weick et al., 1996; Hann et al., 1997; Buchner et al., 1999; Estey et al., 2001; List et al., 2001; Lowenberg et al., 2003). However, in the majority of trials thus far, no alternative approach has proved itself definitively better 
than cytarabine-anthracycline standard therapy. The challenge then remains in determining the type and extent of consolidative or post-remission therapy as an effort to eliminate minimal residual disease and prevent relapse. The choice of therapy for consolidation is largely influenced by prognosis and risk stratification. Several clinical and biologic characteristics help predict the likelihood of disease-free survival for patients with AML. Age, performance status, cytogenetic and molecular features, history of exposure to cytotoxic agents or radiation therapy, and history of prior myelodysplasia or other hematologic disorders all influence prognosis and risk, and thus direct postremission therapy (Estey, 2001; Sekeres et al., 2004; Olesen et al., 2005). In the majority of studies, advanced age (often defined as over age 60) correlates with lower rates of achieving complete remission and shorter disease-free survival, with a population characterized by stronger intrinsic resistance and lower tolerance to chemotherapy (Lowenberg et al., 1996; Leith et al., 1997; Lowenberg et al., 1998). This is an important consideration, as the mean age of AML is 66, and the attendant risk is oftentimes, though not always, linked to performance status and the presence of medical co-morbidities and organ dysfunction. A retrospective analysis of newly diagnosed AML reported increasing 30-day mortality rate with worsening performance status and increased age at diagnosis (Appelbaum et al., 2006). Patients $\leqslant 65$ years had 30-day mortality rates of $5 \%, 4 \%, 9 \%$, and $21 \%$ if they presented with an Eastern Cooperative Oncology Group (ECOG) performance status of $0,1,2$, or 3 , respectively. Patients $>65$ years had rates of $13 \%, 16 \%, 35 \%$, and $60 \%$, respectively. Another study found 28-day mortality to range from $5 \%$ for patients under the age of 50 years with an ECOG performance status $<3$ to $57 \%$ for patients over age 69 with an ECOG performance status of $\geqslant 3$ (Estey, 2001). Those older patients with a worse performance status were also less likely to obtain a complete remission. It is important to note that all of these estimates derive from results of clinical trials, which typically exclude individuals with organ dysfunction and substantially impaired performance status, and thus may underestimate the morbidity and mortality for a large fraction of older patients diagnosed with AML who may not tolerate current treatment options. Nevertheless, subsequent studies have reported lower rates of short-term mortality in older patients undergoing treatment, likely due to improvements in supportive care (Lowenberg et al., 2009).

Those diagnosed with secondary AML, including patients with a history of exposure to cytotoxic agents or radiation therapy and patients with underlying myelodysplasia or hematologic disorders, carry a considerably worse prognosis than those diagnosed with primary AML. Therapy-related myeloid neoplasms (t-MN), including AML, MDS, and myelodysplastic syndrome/myeloproliferative neoplasms (MDS/MPN) account for approximately $10 \%-20 \%$ of all cases of AML, MDS, and MDS/MPN (Smith et al., 1996). Multiple clinical and biological subsets of t-MN have been recognized, and these are correlated with the specific therapy administered for the primary disease. The most common type of t-MN is due to damage from alkylating agents, which react directly with DNA, leading to t-MN with unbalanced aberrations, primarily loss of chromosome material (characteristically, chromosomes 5 and/or 7) (Pedersen-Bjergaard et al., 2008). A second subset of t-MN occurs after therapy with DNA topoisomerase II inhibitors, such as etoposide, doxorubicin, mitoxantrone, etc., resulting in balanced translocations most often involving the MLL gene at 11q23 or the RUNX1 gene at 21q22 (Pedersen-Bjergaard and Philip, 1991; Pui and Relling, 2000; Libura et al., 2005). The prognosis of patients with t-MN is generally worse than for those with de novo AML, as it is more frequently impacted with high-risk cytogenetic and molecular features, rendering the disease more resistant to further therapies. Pre-existing myelodysplastic or myeloproliferative disorders are common in older patients who develop AML, occurring in $24 \%-40 \%$ of cases (Letendre et al., 1998; Estey, 2001; Wahlin et al., 2001; Bello et al., 2011). These pre-existing disorders are often associated with ineffective hematopoiesis and dysfunctional blood cells. By the time that AML emerges, these patients may be colonized by pathogenic flora, threatened by recurrent bleeding episodes, and dependent upon blood product transfusions, leading to worse outcomes than in de novo AML.

An important prognostic tool at diagnosis involves karyotypic evaluation of leukemic cells, which helps distinguish patients into low-, intermediate-, and high-risk groups. Classification into these subgroups can help select appropriate therapy, provide prognostic information, and help clarify underlying molecular pathogenesis so that improved targeted therapies may be developed. These prognostic groups are shown in Table 1. Favorable-risk cytogenetics, such as translocation $15 ; 17$ or those which impact core binding factor (CBF) (translocation 8;21 and inversion 16), are more frequently detected in younger patients and are associated with higher rates of complete remission and lower risk of relapse. Translocation of chromosomes 15 and 17, a feature of acute promyelocytic leukemia, portends a markedly good prognosis, and more than $90 \%$ of patients can be cured, given the exquisite sensitivity of this disease to differentiating agents, such as all-trans retinoic acid (ATRA) and arsenic trioxide. AML with concomitant alterations impacting a transcription factor, $\mathrm{CBF}$, also have relatively improved outcomes with conventional induction therapy, with long-term survival of $60 \%$ or higher. For those with CBF-AML, the post-remission therapy of choice is 3-4 additional chemotherapy cycles with high doses of cytarabine. The high-risk group includes cytogenetic abnormalities that are complex $(\geqslant 3$ unrelated abnormalities), monosomies of chromosome 5 or 7 , deletion of the long arm of 5 or 7 , and abnormalities of the long arm of chromosome 3 . These abnormalities are associated with a survival rate of less than $20 \%$ at five years regardless of age, although they are more frequent in older patients and in those with secondary AML (Appelbaum et al., 2006). Given these poor outcomes, the recommendation for post-remission therapy in eligible patients with high-risk karyotypic features is consolidative allogeneic transplantation.

The remainder comprises $>50 \%$ of patients and are char- 
Table 1. Risk stratification in AML

\begin{tabular}{|c|c|c|c|}
\hline & Clinical characteristics & Cytogenetics & Molecular abnormalities \\
\hline Low & & $\operatorname{inv}(16), t(16 ; 16), t(8 ; 21), t(15 ; 17)$ & $\begin{array}{l}\text { Normal cytogenetics: with NPM1 } \\
\text { mutation or isolated CEBPA } \\
\text { mutation in the absence of FLT3 }\end{array}$ \\
\hline Intermediate & & normal cytogenetics, $+8, \mathrm{t}(9 ; 11)$ & $\begin{array}{l}\text { c-KIT mutation with concurrent } \\
\mathrm{t}(8 ; 21) \text { inv(16), } \mathrm{t}(16 ; 16) \text { : FLT3-ITD } \\
\text { mutation with NPM1 mutation }\end{array}$ \\
\hline High & $\begin{array}{l}\text { Advanced age (age }>60 \text { ), ECOG performance } \\
\text { status } \geqslant 3, \text { history of exposure to cytotoxic } \\
\text { agents/radiation therapy, history of prior } \\
\text { myelodysplasia or other hematologic disorder }\end{array}$ & $\begin{array}{l}\text { Complex karyotypes ( } \geqslant 3 \text { clonal } \\
\text { chromosomal abnormalities), }-5 \text {, } \\
-7,5 q-, 7 q-, 11 q 23 \text { other than } \\
t(9 ; 11) \text { inv(3), } t(3 ; 3), t(6 ; 9), t(9 ; 22)\end{array}$ & $\begin{array}{l}\text { Normal cytogenetics: with } \\
\text { FLT3-ITD mutation in the } \\
\text { absence of NPM1 mutation }\end{array}$ \\
\hline
\end{tabular}

acterized as having an intermediate risk of relapse. This group is the most heterogeneous of all, characterized by myeloblasts with a normal karyotype or cytogenetic abnormalities not included in the definitions of low or high risk. While patients with cytogenetically normal AML have traditionally been included in the intermediate risk group, more sophisticated analyses, including gene mutation and microRNA expression studies, suggest that this group is much more heterogeneous than previously thought. The accumulation of molecular information will provide additional prognostic and therapeutic information within the cytogenetic strata. Gene expression profiling studies can subdivide the large group of patients with normal karyotypes into different biological subsets that appear to have different outcomes (Haferlach et al., 2005).

Although a multitude of genes are currently under investigation regarding their prognostic value, it is currently routine to test for alterations impacting the genes FLT3, NPM1, and $\mathrm{CEBPa}$ at diagnosis. Studies have shown that patients with CEBPa and NPM1 mutations in the absence of an FLT3internal tandem duplication (ITD) mutation have a favorable prognosis, whereas an isolated FLT3-ITD mutation undoubtedly confers a poor prognosis, due to significantly higher risk of relapse (Kottaridis et al., 2001; Preudhomme et al., 2002; Barjesteh van Waalwijk van Doorn-Khosrovani et al., 2003; Bienz et al., 2005; Marcucci et al., 2007; Grimwade et al., 2010). However, recent studies have shown that many patients with AML do not harbor any of these currently recognized gene mutations that are thought to contribute significantly to the pathogenesis of the disease (Shen et al., 2011; Patel et al., 2012). While more efforts are being focused on better classification and prognostication, particularly of the intermediate risk group, none of the current schemes are optimal, suggesting a more complete understanding of the genetic and epigenetic changes relevant to the pathogenesis of AML is necessary. A recently published study analyzed the genome of 200 adult cases of de novo AML (Ley et al., 2013). By organizing mutated genes in AML into functionally related categories, they revealed many potentially important relationships. Notably, certain categories produced a pattern of mutual exclusivity for mutations, suggesting that one mutation in these pathways is adequate for AML pathogenesis. Though not completely understood, this new dataset will undoubtedly be a platform and framework for future studies that attempt to classify both risk and response to therapy in patients with AML. A better understanding of the mechanisms by which these mutations, or lack thereof, produce heightened or blunted sensitivity to treatment has the potential to allow more rational and selective applications of chemotherapy and transplantation. In addition, there is the hope that by identifying critical genes in AML, new therapeutic agents will be able to either specifically target these genes or modify their expression in attempts to improve clinical outcomes (Mrozek et al., 2007).

Approximately $70 \%$ of younger patients typically enter complete remission after one or two induction treatments. However, the therapeutic course and options for older patients is less clear, with poorer outcomes and minimal advances over the years. Although $40 \%-65 \%$ will achieve complete remission, $85 \%$ will relapse within 3 years. This is a large barrier to advancing the field of AML treatment, as the great majority of patients with $\mathrm{AML}$ are older than 60 years. As mentioned above, older age is not only associated with worse prognosis based on functional status and comorbidities, limiting patients' abilities to undergo intensive and more successful regimens, but is also associated with unfavorable cytogenetics and reduced chemotherapy sensitivity. As we are better able to prognosticate and risk-stratify patients, is there a way to alter treatment to more safely administer effective therapies in higher-risk patients? The wealth of emerging molecular data will undoubtedly continue to evolve and will hopefully lead to innovative and successful treatment algorithms. Allogeneic stem cell transplantation, which comprises a large part of AML therapy, is beyond the scope of this review, as the remainder will focus on novel strategies pursued in recent years and which may be the beginning of a new landscape in the therapy of AML.

\section{Hypomethylating agents}

An established approach to the treatment of AML involves the targeting of epigenetic mechanisms that are important in the regulation of cellular processes mediating hematopoietic cell growth and differentiation. DNA cytosine methylation, which modifies gene expression, has been demonstrated to be abnormal in AML, with varying degrees of hypermethylation in 
promoter regions identified in different subgroups correlating with the development of myelodysplasia, leukemogenesis, and drug resistance (Leone et al., 2002; Bullinger et al., 2010; Figueroa et al., 2010a). Methylation of cytosine in the CpG dinucleotide by DNA methyltransferase leads to transcriptional silencing of genes during normal development, and it has emerged as a significant mechanism for the loss of tumor suppressor gene expression in human cancers, including AML (Issa et al., 1997; Santini et al., 2001).

Decitabine and 5-azacitidine, hypomethylating agents, are incorporated into DNA during $S$ phase and irreversibly inhibit DNA methyltransferase, resulting in loss of methylation and reactivation of silenced genes. In a preclinical study, with decitabine at a concentration of $0.5 \mu \mathrm{mol} / \mathrm{L}$, leukemic cells exhibited significant myeloid differentiation compared to vehicle treated cells, which persisted with immature morphology, suggesting that AML cells are in at least some aspects maturation progressed from normal $\mathrm{CD} 34^{+}$precursors, allowing them to be targeted specifically (Negrotto et al., 2012). Azacitidine and decitabine are currently approved for the treatment of MDS on the basis of advanced phase studies that demonstrated improved outcome compared to supportive care alone (Kantarjian et al., 2006; Fenaux et al., 2009).

Multiple studies have also highlighted the utility of both decitabine and 5-azacitidine as appropriate therapeutic alternatives for patients with AML who are perhaps unable to tolerate or decline standard cytotoxic chemotherapy. A large phase III prospective, randomized clinical trial evaluated the effectiveness of 5-azacitidine in treatment of patients with higher-risk myelodysplastic syndrome compared to conventional care, which included best supportive care, low-dose cytarabine, or intensive chemotherapy as selected before randomization (Fenaux et al., 2009). Thirty-two percent of participants met the current WHO criteria for AML. At last follow-up, 82 patients treated with 5-azacitidine had died compared to 113 in the conventional care group. At 2 years, based on Kaplan-Meier estimates, $50.8 \%$ of patients in the 5 -azacitidine group were alive versus $26.2 \%$ in the conventional care group $(P<0.0001)$, a survival advantage seen across all prognostic subgroups. Across the whole study, the median overall survival (OS) was 24.5 months in the 5-azacitidine group versus 15.0 months for the conventional care groups. These results form the basis for the use of 5-azacitidine as therapy for AML.

In a phase II trial evaluating decitabine, older patients with previously untreated AML who were either not candidates for or who refused standard intensive chemotherapy were treated with decitabine $20 \mathrm{mg} / \mathrm{m}^{2}$ for 10 days per cycle (Blum et al., 2010). Notably, $91 \%$ of participants had at least two of the following features: age greater than 70 years, secondary AML, unfavorable karyotype, or performance status greater than 2 . Forty-seven percent achieved complete remission, with an additional nine people achieving complete remission with incomplete cell recovery, making an overall response rate of $64 \%$. Median overall survival was 55 weeks $(95 \% \mathrm{Cl} 36-72$ weeks). To give these results some perspective, in a similar patient population treated with low-dose cytarabine, the comparative standard of care, the complete remission rate was $17 \%$, with a median survival of only 3-4 months (Burnett et al., 2007). A separate multi-center, phase II trial evaluated a comparable patient population with decitabine for 5 days per cycle (Cashen et al., 2010). In fifty-five patients with a mean age of 74 years, all with intermediate or poor-risk cytogenetics without previous treatment, there was a complete response rate of $24 \%$ and an overall median survival rate of 7.7 months. The induction death rates were similar between the five-day and ten-day regimens - the increased treatment duration did not appear to increase early death and showed an improvement in complete response and overall survival. In a population where typically $64 \%$ of patients with AML greater than age 65 years are not treated and subsequently have a median survival time of 1.7 months, hypomethylating therapy does offer a promising therapeutic alternative (Menzin et al., 2006).

Beyond being a potential agent used as first line therapy for patients unable to tolerate cytotoxic therapy, as described above, decitabine may have potential as an epigenetic priming agent given prior to cytotoxic chemotherapy (Issa et al., 2004; Blum et al., 2007; Lubbert et al., 2007). A recent phase I trial evaluated the safety and biologic activity of epigenetic priming with decitabine before standard induction therapy in AML patients with unfavorable risk. The population was predominantly composed of older subjects ( $67 \%>50$ years) with adverse molecular characteristics $(57 \%)$ and at least one adverse risk feature $(83 \%)$. Decitabine was administered for 3, 5, and 7 days of priming $24 \mathrm{~h}$ prior to the standard $7+3$ induction therapy. The authors concluded that the overall complete remission rate of $83 \%$ would suggest that decitabine could be effective as a chemosensitizer by reactivating tumor suppressor gene expression during the window of exposure to cytotoxic induction therapy. This possibility will need to be explored further.

\section{Gemtuzumab ozogamicin}

Gemtuzumab ozogamicin is a humanized anti-CD33 monoclonal antibody linked to a semi-synthetic derivative of calicheamicin, a potent cytotoxic antibiotic (Hinman et al., 1993). CD33 is expressed on approximately $90 \%$ of AML myeloblasts and is downregulated as the myeloid lineage matures, resulting in low-level expression on peripheral granulocytes and tissue macrophages, thus making it a prime target in the treatment of AML. Initial development and data highlighted gemtuzumab ozogamicin as a new therapeutic agent that could be efficacious in newly diagnosed AML, and several phase III studies were designed to test the drug in this setting. The drug was approved under the FDA accelerated approval program in 2000 for treatment as a single agent of patients older than 60 years with AML in first relapse who were not candidates for aggressive chemotherapy (Bross et al., 2001). Approval was based on the results of a phase II study of 142 patients with AML in first relapse - the complete response (including those with incomplete platelet recovery) was $30 \%$, with an overall response 
rate of $26 \%$ in patients over 60 years (Sievers et al., 2001). However, gemtuzumab ozogamicin was withdrawn in 2010 after a phase III comparative controlled trial by, Southwest Oncology Group (SWOG), revealed a toxicity rate that was significantly higher in the gemtuzumab ozogamicin combination therapy group vs. the standard therapy group $(16 / 283=5.7 \%$ vs. $4 / 281=1.4 \% ; P=0.01$ ) (Petersdorf et al., 2013). Since being withdrawn from the market, some studies have supported the efficacy of gemtuzumab ozogamicin in newly diagnosed AML with acceptable toxicity (Burnett et al., 2011, 2012). In an effort to exploit the science behind the drug and minimize toxicities, a recent randomized, open-label, phase III study performed in France studied gemtuzumab ozogamicin, employing fractionated dosing (Castaigne et al., 2012). Instead of the initially studied dosing on days 1 and 14 , the study chose a new regimen based on the repetition of a lower dose of $3 \mathrm{mg} / \mathrm{m}^{2}$ (max dose $5 \mathrm{mg}$ ) on days 1,4 , and 7 . In patients with newly diagnosed AML, aged $50-70$ years, event-free survival, the primary endpoint, was estimated as $17.1 \%(10.8-27.1)$ in the control group versus $40.8 \%(32.8-50.8)$ in the gemtuzumab ozogamicin group (hazard ratio $0.58,0.43-0.78 ; P=0.0003$ ). Secondary endpoints were similarly better with overall survival at $41.9 \%(33.1-53.1)$ versus $53.2 \%$ (44.6-63.5), respectively $(0.69,0.49-0.98 ; P=0.0368)$, and relapse free survival at $22.7 \%(14.5-35.7)$ versus $50.3 \%$ (41.0-61.6), respectively $(0.52,0.36-0.75 ; P=0.0003)$. As mentioned, initial safety concerns regarding gemtuzumab ozogamicin were based on trials using two doses of gemtuzumab ozogamicin at $9 \mathrm{mg} / \mathrm{m}^{2}$, with increased incidence of hepatic veno-occlusive disease. The impressive survival data collected from recent trials in using fractionated dosing, and a lower incidence of liver toxicity, offer a compelling case for possible reconsideration of gemtuzumab ozogamicin as a therapeutic option in AML.

\section{FLT3 tyrosine kinase inhibitors}

FMS-like tyrosine kinase 3 (FLT3) is a receptor tyrosine kinase that acts as a key mediator of early hematopoiesis. Approximately $23 \%$ of patients with AML are found to have an internal tandem duplication (ITD) mutation of the FLT3 gene, which causes constitutive activation of the tyrosine kinase, offsetting negative regulatory functions and causing suppression of apoptosis and dysregulated cell proliferation. As mentioned above, the FLT3-ITD alteration designates an extremely high-risk group with a markedly poor prognosis-studies demonstrating markedly higher rates of relapse and worse disease-free and overall survival rates (as low as $15 \%$ at 5 years) (Kottaridis et al., 2001; Thiede et al., 2002; Levis and Small, 2003; Gale et al., 2008). Targeting the constitutively active FLT3 in these patients with potent tyrosine kinase inhibitors may hold promise in the treatment of a large group of AML patients with an otherwise extremely poor prognosis.

Studied FLT3 inhibitors have had widely varying degrees of success, with the majority of earlier agents producing, at best, temporary reductions in peripheral myeloblasts, with the dura- tion of response ranging from 2 weeks to 5 months (Fiedler et al., 2003; Smith et al., 2004). Clinical trials have established that clinical response strongly correlates with both sustained and effective inhibition. This knowledge has led to a newer generation of FLT3 inhibitors that, in general, exhibit a greater relative specificity for and potency against FLT3, and have improved pharmacokinetics. These agents appear to hold greater promise, especially in the setting of relapsed disease, wherein leukemic cells have been characterized as having a greater mutant FLT3 allele burden, and more addicted to and driven by the constitutively active FLT3 (Pratz et al., 2010). In such a setting, specific and potent FLT3 inhibitors, such as quizartinib (currently in clinical trials), may hold great promise. Preclinical testing of quizartinib revealed both selectivity and potency superior to other FLT3 inhibitors, as well as a longer half-life of approximately 1.5 days allowing for sustained inhibition (Chao et al., 2009; Zarrinkar et al., 2009). In a phase II study of patients with relapsed/refractory AML, preliminary data revealed a composite complete remission (CRc) rate of $45 \%$ (Cortes et al., 2011; Levis et al., 2012). Cohort 1 consisted of patients older than 60 years with relapsed or refractory disease to 1st line chemotherapy, and Cohort 2 consisted of patients greater than 18 years with relapsed or refractory disease to 2nd line chemotherapy or hematopoietic stem cell transplantation (HSCT). Of all those refractory to any prior therapy, the CRc rate was $62 \%$, albeit the remission rate consists of mostly those with incomplete peripheral recovery. Quizartinib allowed $8 \%$ of patients in Cohort 1 , and $30 \%$ of patients in Cohort 2 , to be successfully bridged to a potentially curative HSCT. Interestingly, responses to quizartinib monotherapy were seen in both FLT3-ITD positive and negative patients, with a CRc rate of $44 \%$ and $34 \%$, respectively, likely related to off-target effects of the agent (Bennett et al., 2010). Regardless, this data supports quizartinib as the agent with the highest clinical efficacy amongst all FLT3-target therapy thus far, with acceptable safety parameters. Further studies with quizartinib monotherapy and in combination with other agents are necessary, but this initial data suggests effective and clinically meaningful outcomes in patients with refractory or relapsed AML.

\section{Other novel approaches under study}

A series of other novel approaches have been studied in patients with advanced AML (Table 2). Antisense oligonucleotides are short, synthetic stretches of DNA designed to bind complimentary mRNA strands that correspond to target genes. By binding to the mRNA, the antisense oligonucleotides prevent the translation of the target gene into a protein-the resultant DNA-mRNA complexes are degraded by a ribonuclease (Bennett et al., 2010). Using this mechanism, many genes are currently being investigated as potential targets for treatment in AML. X-linked inhibitor of apoptosis protein (XIAP) is an inhibitor of caspases 3,7 , and 9 , protein mediating the last stages of apoptosis, and has been found to be overexpressed in AML, contributing to chemoresistance (Lacasse et 
Table 2. Established and emerging therapies in AML

\begin{tabular}{|c|c|c|}
\hline $\begin{array}{l}\text { Conventional high-dose } \\
\text { chemotherapy }\end{array}$ & $\begin{array}{l}\text {-Cytarabine and anthracycline-based } \\
\text { induction } \\
\text {-High-dose cytarabine }\end{array}$ & $\begin{array}{l}\text {-Traditional approach reserved for younger patients or those } \\
\text { sufficiently robust to tolerate intensive chemotherapy } \\
\text {-High rates of remission, but high rates of subsequent relapse }\end{array}$ \\
\hline Low-dose chemotherapy & -Low-dose cytarabine & $\begin{array}{l}\text {-Offer disease control for older patients or those who cannot } \\
\text { tolerate intensive induction } \\
\text {-Low rates of remission }\end{array}$ \\
\hline Hypomethylating agents & $\begin{array}{l}\text {-5-azacitidine } \\
\text {-Decitabine }\end{array}$ & $\begin{array}{l}\text {-Improved survival data with } 5 \text {-azacitidine for those with } \\
\text { high-grade MDS or AML with }<30 \% \text { marrow blasts } \\
\text {-High overall response rate, but low CR rate }\end{array}$ \\
\hline Antibody-drug conjugates & -Gemtuzumab ozogamicin & $\begin{array}{l}\text {-Newer dosing approaches have suggested better tolerance } \\
\text { and efficacy }\end{array}$ \\
\hline FLT3 kinase inhibitors & $\begin{array}{l}\text {-Sorafenib } \\
\text {-Quizartenib } \\
\text {-Midostaurin }\end{array}$ & $\begin{array}{l}\text {-Potent FLT3 inhibition can lead to peripheral and marrow } \\
\text { responses } \\
\text {-Still under clinical study }\end{array}$ \\
\hline Emerging novel approaches & $\begin{array}{l}\text {-Aurora kinase inhibitors } \\
\text {-Antisense agents } \\
\text {-MTOR/PI3K inhibitors } \\
\text {-PIM kinase inhibitors } \\
\text {-HDAC inhibitors } \\
\text {-IDH targeted therapies }\end{array}$ & \\
\hline
\end{tabular}

al., 2005). AEG35156 is an antisense agent targeting XIAP and has shown promise in preclinical and clinical trials. A phase $1 / 1 /$ clinical trial of escalating doses of AEG35156 in combination with high-dose cytarabine and idarubacin reinduction therapy was performed in patients with relapsed and refractory AML (Schimmer et al., 2009). Of those who received the highest dose of AEG35156, 47\% were reported to have achieved CR. However, the study's participants varied greatly in the prior regimens they had received, with some patients being refractory to greater than 2 induction regimens. Notably, of those who achieved complete remission, the majority were patients with primary refractory or first-relapse disease. High levels and frequency of target knockdown were observed in patients whose disease had rapidly relapsed or in those refractory to at least 2 induction regimens, but it appears that knockdown of XIAP was not sufficient to result in clinical responses in these patients. In summary, the addition of AEG35156 to reinduction chemotherapy was well tolerated with some suggestion of efficacy in first salvage, but further studies are needed to fully understand and optimize the pharmacokinetics of this and other antisense therapies.

Other novel approaches in treatment are under vigorous study. These include the targeting of various other upregulated pathways and kinases, including aurora kinases, mTOR, PI3 kinase, and PIM kinase. Aurora kinases are a family of proteins known to be integral to the regulation of mitosis and chromosomal segregation, and mutations of all subtypes have been identified in the oncogenic process of both solid and liquid tumors (Meraldi et al., 2004). Alisertib, an aurora A kinase inhibitor, and barasertib, an aurora B selective small molecule inhibitor, have shown promise in early studies (Walsby et al., 2008; Oke et al., 2009; Kelly et al., 2011). FLT3, c-KIT, and RAS mutations, amongst many others, result in constitutive activation of pathways leading to uncontrolled proliferation, a hallmark of all cancers, including AML. Given that many of these mutations cause activation of common downstream pathways, there is growing interest in inhibition of common downstream effectors, including $\mathrm{mTOR}$ and $\mathrm{PI} 3$ kinase. The PI3-K/Akt/mTOR signal transduction cascade is crucial for appropriate cell cycling, replication, and death, with PI3-K, a kinase near the cell surface, being activated by a number of receptor tyrosine kinases (FLT3, EGFR, HER2/neu, etc.) (Witzig and Kaufmann, 2006). Constitutive activation of this pathway has been detected in $50 \%$ to $70 \%$ of patients with AML and is often seen as a downstream effect with FLT3-ITD mutations, providing rationale for the therapeutic targeting of one or more members of this cascade (Brandts et al., 2005; Grandage et al., 2005; Martelli et al., 2006; Yee et al., 2006). Multiple early phase studies have evaluated novel agents that inhibit mTOR in AML, such as rapamycin, temsirolimus, sirolimus, and deforolimus, revealing that these agents are effective in suppressing phosphorylation of downstream targets of mTOR but have modest clinical activity as monotherapy (Mohi et al., 2004; Recher et al., 2005; Callera et al., 2008; Rizzieri et al., 2008). Subsequent trials are now attempting to evaluate the clinical efficacy and safety of mTOR inhibitors combined with traditional cytotoxic agents in patients with poor-risk AML. The serine/threonine kinase PIM (proviral integration site for Moloney murine leukemia), a downstream target of FLT3 found to be upregulated in AML, is also currently under extensive investigation (Kim et al., 2005, 2006). Recent data implicate PIM as an integral component of the FLT3 signaling complex in FLT3-ITD cell lines and inhibition of PIM appears to be directly and preferentially cytotoxic to FLT3-ITD AML cell lines (Fathi et al., 2012).

Other approaches which target the epigenetic landscape are under study. Histone deacetylase, an enzyme that re- 
moves acetyl groups from lysine residues leading to formation of condensed and transcriptionally silenced chromatin, and thus silenced gene expression, is an interesting new target in AML. RUNX1-ETO and CBFb-MYH11 are well characterized fusion genes in AML that cause the aberrant recruitment of histone deacetylase to promoters, resulting in a block in differentiation and uncontrolled proliferation of malignant cells (Kosugi et al., 1999; Amann et al., 2001; Gottlicher et al., 2001; Hiebert et al., 2003; Yang et al., 2004). HDAC inhibitors effectively work as epigenetic modulators, overriding the block in differentiation imposed by the aforementioned fusion genes and inhibiting proliferation of tumor cells by inducing cell arrest, differentiation, and/or apoptosis (Gelmetti et al., 1998).

Finally, mutations of isocitrate dehydrogenase (IDH) genes represent a recently discovered and unique constellation of point mutations in AML. These mutations retard oxidative decarboxylation of isocitrate to alpha-ketoglutarate, conferring novel enzymatic activity and creating excess 2-hydroxyglutarate (2-HG), a recognized oncometabolite (Leonardi et al., 2012). As more is understood about IDH1/2 mutations, it appears that their prognostic impact may vary according to the specific mutational locus, and the presence of other concurrent mutations of other genes, such as NPM1 and FLT3 (Boissel et al., 2010; Green et al., 2010; Marcucci et al., 2010; Paschka et al., 2010; Schnittger et al., 2010; Green et al., 2011). All IDH mutations have shown commonality in the excess production of the metabolite 2-hydroxyglutarate (2-HG). Data suggest that upregulation of $2-\mathrm{HG}$ can lead to aberrant DNA hyper-methylation and epigenetic remodeling, an important consideration for the development of therapeutic agents (Figueroa et al., 2010a; Ward et al., 2010; Lu et al., 2012). There is ongoing interest therefore in the development on novel agents which target altered IDH proteins.

\section{CONCLUSION}

Progress in the treatment and outcomes for patients with acute myeloid leukemia has been limited. This is especially challenging as this is a disease of predominantly older patients, and many older adults, some of whom may exhibit chronic multi-organ dysfunction, or poor performance status, cannot tolerate intensive chemotherapy and harbor leukemic cells that are inherently more resistant. However, in recent years, gene expression profiling has been extensively studied as enhancing prognostication and innovating therapeutic strategies, with the hope that this will ultimately expand therapeutic options for AML. As patients' individual diseases are better understood, a more comprehensive and nuanced understanding of disease and prognosis can lead to more tailored treatments. Many of the new agents under development and techniques stemming from genetic analysis will undoubtedly have a role in future therapy for AML. This is especially important given the heterogeneous and pleiotropic nature of AML, the course and progression of which depends on the interplay of many compensatory cellular mechanisms, with progressive mutations leading to drug resistance and relapse. Although this raises many challenges, there are similarly countless opportunities for the development of novel and effective therapies.

\section{ABBREVIATIONS}

ATRA, all-trans retinoic acid; CBF, core binding factor; ITD, internal tandem duplication; MDS, myelodysplastic syndrome; MPN, myeloproliferative neoplasms; OS, overall survival; t-MN, therapy-related myeloid neoplasms

\section{COMPLIANCE WITH ETHICS GUIDELINES}

Grace Peloquin declares that she has no conflict of interest. Amir Fathi has served on advisory boards with Teva, Agios, and Seattle Genetics, and part of his clinical trial research is funded by Millennium and Seattle Genetics. A portion of the clinical trial research performed by Yi-Bin Chen is funded by Otsuka and Seattle Genetics.

This article does not contain any studies with human or animal subjects performed by the any of the authors.

\section{REFERENCES}

Amann, J. M., Nip, J., Strom, D. K., Lutterbach, B., Harada, H., Lenny, N., Downing, J.R., Meyers, S., and Hiebert, S. W. (2001). ETO, a target of $\mathrm{t}(8 ; 21)$ in acute leukemia, makes distinct contacts with multiple histone deacetylases and binds $\mathrm{mSin} 3 \mathrm{~A}$ through its oligomerization domain. Mol Cell Biol 21, 6470-6483.

Appelbaum, F. R., Gundacker, H., Head, D. R., Slovak, M. L., Willman, C. L., Godwin, J. E., Anderson, J. E., and Petersdorf, S. H. (2006). Age and acute myeloid leukemia. Blood 107, 3481-3485.

Arlin, Z., Case, D. C., Moore, J., Wiernik, P., Feldman, E., Saletan, S., Desai, P., Sia, L., and Cartwright, K. (1990). Randomized multicenter trial of cytosine arabinoside with mitoxantrone or daunorubicin in previously untreated adult patients with acute nonlymphocytic leukemia (ANLL). Lederle Cooperative Group. Leukemia 4, 177-183.

Barjesteh van Waalwijk van Doorn-Khosrovani, S., Erpelinck, C., Meijer, J., van Oosterhoud, S., van Putten, W. L., Valk, P. J., Berna Beverloo, H., Tenen, D. G., Lowenberg, B., and Delwel, R. (2003). Biallelic mutations in the CEBPA gene and low CEBPA expression levels as prognostic markers in intermediate-risk AML. Hematol J 4, 31-40.

Bello, C., Yu, D., Komrokji, R. S., Zhu, W., Wetzstein, G. A., List, A. F., and Lancet, J. E. (2011). Outcomes after induction chemotherapy in patients with acute myeloid leukemia arising from myelodysplastic syndrome. Cancer 117, 1463-1469.

Bennett, C. F., and Swayze, E. E. (2010). RNA targeting therapeutics: molecular mechanisms of antisense oligonucleotides as a therapeutic platform. Annu Rev Pharmacol Toxicol 50, 259-293.

Berman, E., Heller, G., Santorsa, J., McKenzie, S., Gee, T., Kempin, S., Gulati, S., Andreeff, M., Kolitz, J., and Gabrilove, J. (1991). Results of a randomized trial comparing idarubicin and cytosine arabinoside with daunorubicin and cytosine arabinoside in adult patients with newly diagnosed acute myelogenous leukemia. Blood 77, 1666-1674.

Bienz, M., Ludwig, M., Leibundgut, E. O., Mueller, B. U., Ratschiller, D., Solenthaler, M., Fey, M. F., and Pabst, T. (2005). Risk assessment in patients with acute myeloid leukemia and a normal karyotype. 
Clin Cancer Res 11, 1416-1424.

Bishop, J. F., Lowenthal, R. M., Joshua, D., Matthews, J. P., Todd, D., Cobcroft, R., Whiteside, M. G., Kronenberg, H., Ma, D., and Dodds, A. (1990). Etoposide in acute nonlymphocytic leukemia. Australian Leukemia Study Group. Blood 75, 27-32.

Bishop J.F., Matthews J.P., Young G.A., Szer J., Gillett A., Joshua D., Bradstock K., Enno A., Wolf M.M., Fox R., et al. (1996). A randomized study of high-dose cytarabine in induction in acute myeloid leukemia. Blood 87, 1710-1717.

Blum W., Garzon R., Klisovic R.B., Schwind S., Walker A., Geyer S., Liu S., Havelange V., Becker H., Schaaf L., et al. (2010). Clinical response and miR-29b predictive significance in older $A M L$ patients treated with a 10-day schedule of decitabine. Proc Natl Acad Sci U S A 107, 7473-7478.

Blum W., Klisovic R.B., Hackanson B., Liu Z., Liu S., Devine H., Vukosavljevic T., Huynh L., Lozanski G., Kefauver C., et al. (2007). Phase I study of decitabine alone or in combination with valproic acid in acute myeloid leukemia. J Clin Oncol 25, 3884-3891.

Boissel N., Nibourel O., Renneville A., Gardin C., Reman O., Contentin N., Bordessoule D., Pautas C., de Revel T., Quesnel B., et al. (2010). Prognostic impact of isocitrate dehydrogenase enzyme isoforms 1 and 2 mutations in acute myeloid leukemia: a study by the Acute Leukemia French Association group. J Clin Oncol 28, 3717-3723.

Brandts C.H., Sargin B., Rode M., Biermann C., Lindtner B., Schwäble J., Buerger H., Müller-Tidow C., Choudhary C., McMahon M., et al. (2005). Constitutive activation of Akt by Flt3 internal tandem duplications is necessary for increased survival, proliferation, and myeloid transformation. Cancer Res 65, 9643-9650.

Bross P.F., Beitz J., Chen G., Chen X.H., Duffy E., Kieffer L., Roy S., Sridhara R., Rahman A., Williams G., et al. (2001). Approval summary: gemtuzumab ozogamicin in relapsed acute myeloid leukemia. Clin Cancer Res 7, 1490-1496.

Bullinger, L., Ehrich, M., Döhner, K., Schlenk, R. F., Döhner, H., Nelson, M. R., and van den Boom, D. (2010). Quantitative DNA methylation predicts survival in adult acute myeloid leukemia. Blood 115, 636-642.

Burnett, A. K., Hills, R. K., Milligan, D., Kjeldsen, L., Kell, J., Russell, N. H., Yin, J. A., Hunter, A., Goldstone, A. H., and Wheatley, K. (2011). Identification of patients with acute myeloblastic leukemia who benefit from the addition of gemtuzumab ozogamicin: results of the MRC AML15 trial. J Clin Oncol 29, 369-377.

Burnett, A. K., Milligan, D., Prentice, A. G., Goldstone, A. H., McMullin, M. F., Hills, R. K., and Wheatley, K. (2007). A comparison of lowdose cytarabine and hydroxyurea with or without all-trans retinoic acid for acute myeloid leukemia and high-risk myelodysplastic syndrome in patients not considered fit for intensive treatment. Cancer 109, 1114-1124.

Burnett A.K., Russell N.H., Hills R.K., Kell J., Freeman S., Kjeldsen L., Hunter A.E., Yin J., Craddock C.F., Dufva I.H., et al. (2012). Addition of gemtuzumab ozogamicin to induction chemotherapy improves survival in older patients with acute myeloid leukemia. J Clin Oncol 30, 3924-3931.

Büchner T., Hiddemann W., Wörmann B., Löffler H., Gassmann W., Haferlach T., Fonatsch C., Haase D., Schoch C., Hossfeld D., et al. (1999). Double induction strategy for acute myeloid leukemia: the effect of high-dose cytarabine with mitoxantrone instead of standard-dose cytarabine with daunorubicin and 6-thioguanine: a randomized trial by the German AML Cooperative Group. Blood 93, 4116-4124.

Callera, F., Lopes, C. O., Rosa, E. S., and Mulin, C. C. (2008). Lack of antileukemic activity of rapamycin in elderly patients with acute myeloid leukemia evolving from a myelodysplastic syndrome. Leuk Res 32, 1633-1634.

Cashen, A. F., Schiller, G. J., O'Donnell, M. R., and DiPersio, J. F. (2010). Multicenter, phase II study of decitabine for the first-line treatment of older patients with acute myeloid leukemia. J Clin Oncol 28, 556-561.

Castaigne S., Pautas C., Terré C., Raffoux E., Bordessoule D., Bastie J.N., Legrand O., Thomas X., Turlure P., Reman O., et al. (2012). Effect of gemtuzumab ozogamicin on survival of adult patients with de-novo acute myeloid leukaemia (ALFA-0701): a randomised, open-label, phase 3 study. Lancet 379, 1508-1516.

Chao Q., Sprankle K.G., Grotzfeld R.M., Lai A.G., Carter T.A., Velasco A.M., Gunawardane R.N., Cramer M.D., Gardner M.F., James J., et al. (2009). Identification of N-(5-tert-butyl-isoxazol-3-yl)-N'-\{4-[7-(2morpholin-4-yl-ethoxy)imidazo[2,1-b][1,3]benzothiazol-2-yl]phenyl\} urea dihydrochloride (AC220), a uniquely potent, selective, and efficacious FMS-like tyrosine kinase-3 (FLT3) inhibitor. J Med Chem 52, 7808-7816

Cortes, J., Perl, A., Smith, C., Kovacsovics, T., Dombret, H., Dohner, H., Steffen, B., Pigneux, A., Rousselot, P., Krauter, J., et al. (2011). A phase II open-label, AC220 monotherapy efficacy (ACE) study in patients with acute myeloid leukemia (AML) with FLT3-ITD activating mutations: Updated interim results. Blood 118, Abstract 2576.

Dillman, R. O., Davis, R. B., Green, M. R., Weiss, R. B., Gottlieb, A. J., Caplan, S., Kopel, S., Preisler, H., Mclntyre, O. R., and Schiffer, C. (1991). A comparative study of two different doses of cytarabine for acute myeloid leukemia: a phase III trial of Cancer and Leukemia Group B. Blood 78, 2520-2526.

Estey, E. H. (2001). Therapeutic options for acute myelogenous leukemia. Cancer 92, 1059-1073.

Estey, E. H., Thall, P. F., Cortes, J. E., Giles, F. J., O'Brien, S., Pierce, S. A., Wang, X., Kantarjian, H. M., and Beran, M. (2001). Comparison of idarubicin + ara-C-, fludarabine + ara-C-, and topotecan + araC-based regimens in treatment of newly diagnosed acute myeloid leukemia, refractory anemia with excess blasts in transformation, or refractory anemia with excess blasts. Blood 98, 3575-3583.

Fathi A.T., Arowojolu O., Swinnen I., Sato T., Rajkhowa T., Small D., Marmsater F., Robinson J.E., Gross S.D., Martinson M., et al. (2012). A potential therapeutic target for FLT3-ITD AML: PIM1 kinase. Leuk Res 36, 224-231.

Fenaux P., Mufti G.J., Hellstrom-Lindberg E., Santini V., Finelli C., Giagounidis A., Schoch R., Gattermann N., Sanz G., List A., et al. (2009). Efficacy of azacitidine compared with that of conventional care regimens in the treatment of higher-risk myelodysplastic syndromes: a randomised, open-label, phase III study. Lancet Oncol 10, 223-232.

Fiedler W., Mesters R., Tinnefeld H., Loges S., Staib P., Duhrsen U., Flasshove M., Ottmann O.G., Jung W., Cavalli F., et al. (2003). A phase 2 clinical study of SU5416 in patients with refractory acute myeloid leukemia. Blood 102, 2763-2767.

Figueroa M.E., Abdel-Wahab O., Lu C., Ward P.S., Patel J., Shih A., Li Y., Bhagwat N., Vasanthakumar A., Fernandez H.F., et al. (2010b). Leukemic IDH1 and IDH2 mutations result in a hypermethylation 
phenotype, disrupt TET2 function, and impair hematopoietic differentiation. Cancer Cell 18, 553-567.

Figueroa M.E., Lugthart S., Li Y., Erpelinck-Verschueren C., Deng X., Christos P.J., Schifano E., Booth J., van Putten W., Skrabanek L., et al. (2010a). DNA methylation signatures identify biologically distinct subtypes in acute myeloid leukemia. Cancer Cell 17, 13-27.

Gale, R. E., Green, C., Allen, C., Mead, A. J., Burnett, A. K., Hills, R. K., Linch, D. C., and Medical Research Council Adult Leukaemia Working Party. (2008). The impact of FLT3 internal tandem duplication mutant level, number, size, and interaction with NPM1 mutations in a large cohort of young adult patients with acute myeloid leukemia. Blood 111, 2776-2784.

Gelmetti, V., Zhang, J., Fanelli, M., Minucci, S., Pelicci, P. G., and Lazar, M. A. (1998). Aberrant recruitment of the nuclear receptor corepressor-histone deacetylase complex by the acute myeloid leukemia fusion partner ETO. Mol Cell Biol 18, 7185-7191.

Grandage, V. L., Gale, R. E., Linch, D. C., and Khwaja, A. (2005). $\mathrm{PI3}-$ kinase/Akt is constitutively active in primary acute myeloid leukaemia cells and regulates survival and chemoresistance via NFkappaB, Mapkinase and p53 pathways. Leukemia 19, 586-594.

Green, C. L., Evans, C. M., Hills, R. K., Burnett, A. K., Linch, D. C., and Gale, R. E. (2010). The prognostic significance of IDH1 mutations in younger adult patients with acute myeloid leukemia is dependent on FLT3/ITD status. Blood 116, 2779-2782.

Green, C. L., Evans, C. M., Zhao, L., Hills, R. K., Burnett, A. K., Linch, D. C., and Gale, R. E. (2011). The prognostic significance of IDH2 mutations in AML depends on the location of the mutation. Blood $118,409-412$

Grimwade, D., Hills, R. K., Moorman, A. V., Walker, H., Chatters, S., Goldstone, A. H., Wheatley, K., Harrison, C. J., Burnett, A. K., and National Cancer Research Institute Adult Leukaemia Working Group. (2010). Refinement of cytogenetic classification in acute myeloid leukemia: determination of prognostic significance of rare recurring chromosomal abnormalities among 5876 younger adult patients treated in the United Kingdom Medical Research Council trials. Blood 116, 354-365.

Göttlicher M., Minucci S., Zhu P., Krämer O.H., Schimpf A., Giavara S., Sleeman J.P., Lo Coco F., Nervi C., Pelicci P.G., et al. (2001). Valproic acid defines a novel class of HDAC inhibitors inducing differentiation of transformed cells. EMBO J 20,6969-6978.

Haferlach, T., Kohlmann, A., Schnittger, S., Dugas, M., Hiddemann, W., Kern, W., and Schoch, C. (2005). Global approach to the diagnosis of leukemia using gene expression profiling. Blood 106, 1189-1198.

Hann, I. M., Stevens, R. F., Goldstone, A. H., Rees, J. K., Wheatley, K., Gray, R. G., and Burnett, A. K. (1997). Randomized comparison of DAT versus ADE as induction chemotherapy in children and younger adults with acute myeloid leukemia. Results of the Medical Research Council's 10th AML trial (MRC AML10). Adult and Childhood Leukaemia Working Parties of the Medical Research Council. Blood 89, 2311-2318.

Hiebert, S. W., Reed-Inderbitzin, E. F., Amann, J., Irvin, B., Durst, K., and Linggi, B. (2003). The $t(8 ; 21)$ fusion protein contacts corepressors and histone deacetylases to repress the transcription of the p14ARF tumor suppressor. Blood Cells Mol Dis 30, 177-183.

Hinman, L. M., Hamann, P. R., Wallace, R., Menendez, A. T., Durr, F. E., and Upeslacis, J. (1993). Preparation and characterization of monoclonal antibody conjugates of the calicheamicins: a novel and potent family of antitumor antibiotics. Cancer Res 53, 3336-3342.

Issa, J. P., Baylin, S. B., and Herman, J. G. (1997). DNA methylation changes in hematologic malignancies: biologic and clinical implications. Leukemia 11 Suppl 1, S7-11.

Issa J.P., Garcia-Manero G., Giles F.J., Mannari R., Thomas D., Faderl S., Bayar E., Lyons J., Rosenfeld C.S., Cortes J., et al. (2004). Phase 1 study of low-dose prolonged exposure schedules of the hypomethylating agent 5-aza-2'-deoxycytidine (decitabine) in hematopoietic malignancies. Blood 103, 1635-1640.

Kantarjian H., Issa J.P., Rosenfeld C.S., Bennett J.M., Albitar M., DiPersio J., Klimek V., Slack J., de Castro C., Ravandi F., et al. (2006). Decitabine improves patient outcomes in myelodysplastic syndromes: results of a phase III randomized study. Cancer 106, 1794-1803.

Kelly, K., Padmanabhan, S., Goy, A., Berdeja, J.G., Reeder, C.B., McDonagh, K.T., Xiaofei Zhou, X., Danaee, H., Xiao, H., Benaim, E., et al. (2011). Results from a Phase I multicenter trial of Alisertib (MLN8237) - an investigational aurora A kinase inhibitor - in patients with advanced hematologic malignancies. 53rd ASH Annual Meeting and Exposition. Abstract 2477.

Kim, K. T., Baird, K., Ahn, J. Y., Meltzer, P., Lilly, M., Levis, M., and Small, D. (2005). Pim-1 is up-regulated by constitutively activated FLT3 and plays a role in FLT3-mediated cell survival. Blood 105, 1759-1767.

Kim, K. T., Levis, M., and Small, D. (2006). Constitutively activated FLT3 phosphorylates BAD partially through pim-1. $\mathrm{Br} \mathrm{J}$ Haematol 134, 500-509.

Kosugi H., Towatari M., Hatano S., Kitamura K., Kiyoi H., Kinoshita T., Tanimoto M., Murate T., Kawashima K., Saito H., et al. (1999). Histone deacetylase inhibitors are the potent inducer/enhancer of differentiation in acute myeloid leukemia: a new approach to antileukemia therapy. Leukemia 13, 1316-1324.

Kottaridis P.D., Gale R.E., Frew M.E., Harrison G., Langabeer S.E., Belton A.A., Walker H., Wheatley K., Bowen D.T., Burnett A.K., et al. (2001). The presence of a FLT3 internal tandem duplication in patients with acute myeloid leukemia (AML) adds important prognostic information to cytogenetic risk group and response to the first cycle of chemotherapy: analysis of 854 patients from the United Kingdom Medical Research Council AML 10 and 12 trials. Blood 98, 1752-1759.

Lacasse, E. C., Kandimalla, E. R., Winocour, P., Sullivan, T., Agrawal, S., Gillard, J. W., and Durkin, J. (2005). Application of XIAP antisense to cancer and other proliferative disorders: development of AEG35156/ GEM640. Ann N Y Acad Sci 1058, 215-234.

Leith, C. P., Kopecky, K. J., Godwin, J., McConnell, T., Slovak, M. L., Chen, I. M., Head, D. R., Appelbaum, F. R., and Willman, C. L. (1997). Acute myeloid leukemia in the elderly: assessment of multidrug resistance (MDR1) and cytogenetics distinguishes biologic subgroups with remarkably distinct responses to standard chemotherapy. A Southwest Oncology Group study. Blood 89, 3323-3329.

Leonardi, R., Subramanian, C., Jackowski, S., and Rock, C. O. (2012). Cancer-associated isocitrate dehydrogenase mutations inactivate NADPH-dependent reductive carboxylation. J Biol Chem 287, 14615-14620.

Leone, G., Teofili, L., Voso, M. T., and Lübbert, M. (2002). DNA methylation and demethylating drugs in myelodysplastic syndromes and 
secondary leukemias. Haematologica 87, 1324-1341.

Letendre, L., Noel, P., Litzow, M. R., Hoagland, H. C., and Tefferi, A. (1998). Treatment of acute myelogenous leukemia in the older patient with attenuated high-dose ara-C. Am J Clin Oncol 21, 142144.

Levis, M. and Small, D. (2003). FLT3: ITDoes matter in leukemia. Leukemia. 17(9), 1738-1752.

Levis, M.J., Perl, A.E., Dombret, H., Döhner, H., Steffen, B., Rousselot, P., Martinelli, P., Estey, E.H., Burnett, A.K., Gammon, G., et al. (2012). Final results of a phase 2 open-label, monotherapy efficacy and safety study of quizartinib (AC22) in patients with FLT3-ITD positive or negative relapsed/refractory acute myeloid leukemia after second-line chemotherapy or hematopoietic stem cell transplantation. Blood 120, Abstract 673.

Ley, T. J. (2013). Genomic and epigenomic landscapes of adult de novo acute myeloid leukemia. N Engl J Med 368, 2059-2074.

Libura, J., Slater, D. J., Felix, C. A., and Richardson, C. (2005). Therapy-related acute myeloid leukemia-like MLL rearrangements are induced by etoposide in primary human $\mathrm{CD} 34^{+}$cells and remain stable after clonal expansion. Blood 105, 2124-2131.

List A.F., Kopecky K.J., Willman C.L., Head D.R., Persons D.L., Slovak M.L., Dorr R., Karanes C., Hynes H.E., Doroshow J.H., et al. (2001). Benefit of cyclosporine modulation of drug resistance in patients with poor-risk acute myeloid leukemia: a Southwest Oncology Group study. Blood 98, 3212-3220.

Lu C., Ward P.S., Kapoor G.S., Rohle D., Turcan S., Abdel-Wahab O., Edwards C.R., Khanin R., Figueroa M.E., Melnick A., et al. (2012). IDH mutation impairs histone demethylation and results in a block to cell differentiation. Nature 483, 474-478.

Lubbert, M., Ruter, B., Claus, R., Schmid, M., Germing, U., Eimermacher, H., Ganser, A., Platzbecker, U., Galm, O., Brugger, W., et al. (2007). Continued low-dose decitabine (DAC) is an active firstline treatment in all cytogenetic subgroups of older AML patients: Results of the FR00331 multicenter phase II study. ASH Annual Meeting Abstracts 110, 300.

Löwenberg, B. (1996). Treatment of the elderly patient with acute myeloid leukaemia. Baillière's clinical haematology 9, 147-159.

Löwenberg, B., Downing, J. R., and Burnett, A. (1999). Acute myeloid leukemia. N Engl J Med 341, 1051-1062.

Löwenberg, B., Ossenkoppele, G. J., van Putten, W., Schouten H.C., Graux C., Ferrant A., Sonneveld P., Maertens J., Jongen-Lavrencic M., von Lilienfeld-Toal M., et al. (2009). High-dose daunorubicin in older patients with acute myeloid leukemia. N Engl J Med 361, 1235-1248.

Löwenberg, B., Suciu, S., Archimbaud, E., Haak H., Stryckmans P., de Cataldo R., Dekker A.W., Berneman Z.N., Thyss A., van der Lelie J., et al. (1998). Mitoxantrone versus daunorubicin in inductionconsolidation chemotherapy--the value of low-dose cytarabine for maintenance of remission, and an assessment of prognostic factors in acute myeloid leukemia in the elderly: final report. European Organization for the Research and Treatment of Cancer and the Dutch-Belgian Hemato-Oncology Cooperative Hovon Group. J Clin Oncol 16, 872-881.

Löwenberg, B., van Putten, W., Theobald, M., Gmür J., Verdonck L., Sonneveld P., Fey M., Schouten H., de Greef G., Ferrant A., et al. (2003). Effect of priming with granulocyte colony-stimulating factor on the outcome of chemotherapy for acute myeloid leukemia. $\mathrm{N}$
Engl J Med 349, 743-752.

Marcucci, G., Maharry, K., Whitman, S. P., Vukosavljevic T., Paschka P., Langer C., Mrózek K., Baldus C.D., Carroll A.J., Powell B.L., et al. (2007). High expression levels of the ETS-related gene, ERG, predict adverse outcome and improve molecular risk-based classification of cytogenetically normal acute myeloid leukemia: a Cancer and Leukemia Group B Study. J Clin Oncol 25, 3337-3343.

Marcucci, G., Maharry, K., Wu, Y. Z., Radmacher M.D., Mrózek K., Margeson D., Holland K.B., Whitman S.P., Becker H., Schwind S., et al. (2010). IDH1 and IDH2 gene mutations identify novel molecular subsets within de novo cytogenetically normal acute myeloid leukemia: a Cancer and Leukemia Group B study. J Clin Oncol 28, 2348-2355.

Martelli, A. M., Nyåkern, M., Tabellini, G., Bortul, R., Tazzari, P. L., Evangelisti, C., and Cocco, L. (2006). Phosphoinositide 3-kinase/ Akt signaling pathway and its therapeutical implications for human acute myeloid leukemia. Leukemia 20, 911-928.

Menzin, J., Boulenger, L., Karsten, V., and Cahill, A. (2006). Effects of initial treatment on survival among elderly AML patients: Findings from the SEER-Medicare Database. Blood 108, Abstract 1973.

Meraldi, P., Honda, R., and Nigg, E. A. (2004). Aurora kinases link chromosome segregation and cell division to cancer susceptibility. Curr Opin Genet Dev. 14(1), 29-36.

Mohi, M. G., Boulton, C., Gu, T. L., Sternberg, D. W., Neuberg, D., Griffin, J. D., Gilliland, D. G., and Neel, B. G. (2004). Combination of rapamycin and protein tyrosine kinase (PTK) inhibitors for the treatment of leukemias caused by oncogenic PTKs. Proc Natl Acad Sci U S A. 101(9), 3130-3135.

Mrózek, K., Marcucci, G., Paschka, P., Whitman, S. P., and Bloomfield, C. D. (2007). Clinical relevance of mutations and gene-expression changes in adult acute myeloid leukemia with normal cytogenetics: are we ready for a prognostically prioritized molecular classification? Blood 109, 431-448.

Negrotto, S., Ng, K. P., Jankowska, A. M., Bodo, J., Gopalan, B., Guinta, K., Mulloy, J. C., His, E., Maciejewski, J., and Saunthararajah, Y. (2012). CpG methylation patterns and decitabine treatment response in acute myeloid leukemia cells and normal hematopoietic precursors. Leukemia 26, 244-254.

Oke, A., Pearce, D., Wilkinson, R. W., Crafter, C., Odedra, R., Cavenagh, J., Fitzgibbon, J., Lister, A. T., Joel, S., and Bonnet, D. (2009). AZD1152 rapidly and negatively affects the growth and survival of human acute myeloid leukemia cells in vitro and in vivo. Cancer Res 69, 4150-4158.

Olesen, L. H., Aggerholm, A., Andersen, B. L., Nyvold, C. G., Guldberg, P., Nørgaard, J. M., and Hokland, P. (2005). Molecular typing of adult acute myeloid leukaemia: significance of translocations, tandem duplications, methylation, and selective gene expression profiling. Br J Haematol 131, 457-467.

Paschka, P., Schlenk, R. F., Gaidzik, V. I., Habdank M., Krönke J., Bullinger L., Späth D., Kayser S., Zucknick M., Götze K., et al. (2010). IDH1 and IDH2 mutations are frequent genetic alterations in acute myeloid leukemia and confer adverse prognosis in cytogenetically normal acute myeloid leukemia with NPM1 mutation without FLT3 internal tandem duplication. J Clin Oncol 28, 3636-3643.

Patel, J. P., Gonen, M., Figueroa, M. E., Fernandez H., Sun Z., Racevskis J., Van Vlierberghe P., Dolgalev I., Thomas S., Aminova O., et al. (2012). Prognostic relevance of integrated genetic profiling 
in acute myeloid leukemia. N Engl J Med. 366, 1079-1089.

Pedersen-Bjergaard, J., Andersen, M. K., Andersen, M. T., and Christiansen, D. H. (2008). Genetics of therapy-related myelodysplasia and acute myeloid leukemia. Leukemia 22, 240-248.

Pedersen-Bjergaard, J. and Philip, P. (1991). Balanced translocations involving chromosome bands 11q23 and 21q22 are highly characteristic of myelodysplasia and leukemia following therapy with cytostatic agents targeting at DNA-topoisomerase II. Blood 78, 1147-1148.

Petersdorf, S. H., Kopecky, K. J., Slovak, M., Willman C., Nevill T., Brandwein J., Larson R.A., Erba H.P., Stiff P.J., Stuart R.K., et al. (2013). A phase 3 study of gemtuzumab ozogamicin during induction and postconsolidation therapy in younger patients with acute myeloid leukemia. Blood 121, 4854-4860.

Pratz, K. W., Sato, T., Murphy, K. M., Stine, A., Rajkhowa, T., and Levis, M. (2010). FLT3-mutant allelic burden and clinical status are predictive of response to FLT3 inhibitors in AML. Blood 115, 1425-1432.

Preudhomme, C., Sagot, C., Boissel, N., Cayuela J.M., Tigaud I., de Botton S., Thomas X., Raffoux E., Lamandin C., Castaigne S., et al. (2002). Favorable prognostic significance of CEBPA mutations in patients with de novo acute myeloid leukemia: a study from the Acute Leukemia French Association (ALFA). Blood 100, 27172723.

Pui, C. H. and Relling, M. V. (2000). Topoisomerase II inhibitor-related acute myeloid leukaemia. Br J Haematol 109, 13-23.

Rizzieri, D. A., Feldman, E., Dipersio, J. F., Gabrail, N., Stock, W., Strair, R., Rivera, V. M., Albitar, M., Bedrosian, C. L., and Giles, F. J. (2008). A phase 2 clinical trial of deforolimus (AP23573, MK-8669), a novel mammalian target of rapamycin inhibitor, in patients with relapsed or refractory hematologic malignancies. Clin Cancer Res 14, 2756-2762.

Rowe, J. M. and Tallman, M. S. (1997). Intensifying induction therapy in acute myeloid leukemia: has a new standard of care emerged? Blood 90, 2121-2126.

Récher, C., Beyne-Rauzy, O., Demur, C., Chicanne, G., Dos Santos, C., Mas, V. M., Benzaquen, D., Laurent, G., Huguet, F., and Payrastre, B. (2005). Antileukemic activity of rapamycin in acute myeloid leukemia. Blood 105, 2527-2534.

Santini, V., Kantarjian, H. M., and Issa, J. P. (2001). Changes in DNA methylation in neoplasia: pathophysiology and therapeutic implications. Ann Intern Med 134, 573-586.

Schimmer, A. D., Estey, E. H., Borthakur, G., Carter B.Z., Schiller G.J., Tallman M.S., Altman J.K., Karp J.E., Kassis J., Hedley D.W., et al. (2009). Phase I/II trial of AEG35156 X-linked inhibitor of apoptosis protein antisense oligonucleotide combined with idarubicin and cytarabine in patients with relapsed or primary refractory acute myeloid leukemia. J Clin Oncol 27, 4741-4746.

Schnittger, S., Haferlach, C., Ulke, M., Alpermann, T., Kern, W., and Haferlach, T. (2010). IDH1 mutations are detected in $6.6 \%$ of 1414 AML patients and are associated with intermediate risk karyotype and unfavorable prognosis in adults younger than 60 years and unmutated NPM1 status. Blood 116, 5486-5496.

Sekeres, M. A., Peterson, B., Dodge, R. K., Mayer R.J., Moore J.O., Lee E.J., Kolitz J., Baer M.R., Schiffer C.A., Carroll A.J., et al. (2004). Differences in prognostic factors and outcomes in African Americans and whites with acute myeloid leukemia. Blood 103, 4036-4042.
Shen, Y., Zhu, Y. M., Fan, X., Shi J.Y., Wang Q.R., Yan X.J., Gu Z.H., Wang Y.Y., Chen B., Jiang C.L., et al. (2011). Gene mutation patterns and their prognostic impact in a cohort of 1185 patients with acute myeloid leukemia. Blood 118, 5593-5603.

Sievers, E. L., Larson, R. A., Stadtmauer, E. A. , Estey E., Löwenberg B., Dombret H., Karanes C., Theobald M., Bennett J.M., Sherman M.L., et al. (2001). Efficacy and safety of gemtuzumab ozogamicin in patients with CD33-positive acute myeloid leukemia in first relapse. J Clin Oncol 19, 3244-3254.

Smith, B. D., Levis, M., Beran, M., Giles, F., Kantarjian, H., Berg, K., Murphy, K. M., Dauses, T., Allebach, J., and Small, D. (2004). Single-agent CEP-701, a novel FLT3 inhibitor, shows biologic and clinical activity in patients with relapsed or refractory acute myeloid leukemia. Blood 103, 3669-3676.

Smith, M. A., McCaffrey, R. P., and Karp, J. E. (1996). The secondary leukemias: challenges and research directions. J Natl Cancer Inst 88, 407-418.

Thiede, C., Steudel, C., Mohr, B., Schaich M., Schäkel U., Platzbecker U., Wermke M., Bornhäuser M., Ritter M., Neubauer A., et al. (2002). Analysis of FLT3-activating mutations in 979 patients with acute myelogenous leukemia: association with FAB subtypes and identification of subgroups with poor prognosis. Blood 99, 4326-4335.

Vogler, W. R., Velez-Garcia, E., Weiner, R. S., Flaum, M. A., Bartolucci, A. A., Omura, G. A., Gerber, G. A., and Banks, P. L. (1992). A phase III trial comparing idarubicin and daunorubicin in combination with cytarabine in acute myelogenous leukemia: a Southeastern Cancer Study Group Study. J Clin Oncol 10, 1103-1111.

Wahlin, A., Markevärn, B., Golovleva, I., and Nilsson, M. (2001). Prognostic significance of risk group stratification in elderly patients with acute myeloid leukaemia. Br J Haematol 115, 25-33.

Walsby, E., Walsh, V., Pepper, C., Burnett, A., and Mills, K. (2008). Effects of the aurora kinase inhibitors AZD1152-HQPA and ZM447439 on growth arrest and polyploidy in acute myeloid leukemia cell lines and primary blasts. Haematologica 93, 662-669.

Ward, P. S., Patel, J., Wise, D. R., Abdel-Wahab O., Bennett B.D., Coller H.A., Cross J.R., Fantin V.R., Hedvat C.V., Perl A.E., et al. (2010). The common feature of leukemia-associated IDH1 and IDH2 mutations is a neomorphic enzyme activity converting alphaketoglutarate to 2-hydroxyglutarate. Cancer Cell 17, 225-234.

Weick, J. K., Kopecky, K. J., Appelbaum, F. R., Head D.R., Kingsbury L.L., Balcerzak S.P., Bickers J.N., Hynes H.E., Welborn J.L., Simon S.R., et al. (1996). A randomized investigation of high-dose versus standard-dose cytosine arabinoside with daunorubicin in patients with previously untreated acute myeloid leukemia: a Southwest Oncology Group study. Blood 88, 2841-2851.

Wiernik, P. H., Banks, P. L., Case, D. C., Arlin, Z. A., Periman, P. O., Todd, M. B., Ritch, P. S., Enck, R. E., and Weitberg, A. B. (1992). Cytarabine plus idarubicin or daunorubicin as induction and consolidation therapy for previously untreated adult patients with acute myeloid leukemia. Blood 79, 313-319.

Witzig, T. E. and Kaufmann, S. H. (2006). Inhibition of the phosphatidylinositol 3-kinase/mammalian target of rapamycin pathway in hematologic malignancies. Curr Treat Options Oncol 7, 285-294.

Yang, G., Khalaf, W., van de Locht, L., Jansen, J. H., van der Reijden, B. A., Müller-Tidow, C., Delwel, H. R., Serve, H., Clapp, D. W., and Hiebert, S. W. (2004). Epigenetic regulation of tumor suppressors in t(8:21)-containing AML. Ann Hematol 83, 329-330. 
Yang, J., Ikezoe, T., Nishioka, C., Tasaka T., Taniguchi A., Kuwayama Y., Komatsu N., Bandobashi K., Togitani K., Koeffler H.P., et al. (2007). AZD1152, a novel and selective aurora B kinase inhibitor, induces growth arrest, apoptosis, and sensitization for tubulin depolymerizing agent or topoisomerase II inhibitor in human acute leukemia cells in vitro and in vivo. Blood 110, 2034-2040.

Yates, J., Glidewell, O., Wiernik, P., Cooper M.R., Steinberg D., Dosik H., Levy R., Hoagland C., Henry P., Gottlieb A., et al. (1982). Cytosine arabinoside with daunorubicin or adriamycin for therapy of acute myelocytic leukemia: a CALGB study. Blood 60, 454-462.
Yee, K.W., Zeng, Z., Konopleva, M., Verstovsek S., Ravandi F., Ferrajoli A., Thomas D., Wierda W., Apostolidou E., Albitar M., et al. (2006). Phase I/II study of the mammalian target of rapamycin inhibitor everolimus (RAD001) in patients with relapsed or refractory hematologic malignancies. Clin Cancer Res 12, 5165-5173.

Zarrinkar, P. P., Gunawardane, R. N., Cramer, M. D., Gardner M.F., Brigham D., Belli B., Karaman M.W., Pratz K.W., Pallares G., Chao Q., et al. (2009). AC220 is a uniquely potent and selective inhibitor of FLT3 for the treatment of acute myeloid leukemia (AML). Blood 114, 2984-2992. 